\title{
Glucocorticoids promote structural and functional maturation of foetal cardiomyocytes: a role for PGC-1a
}

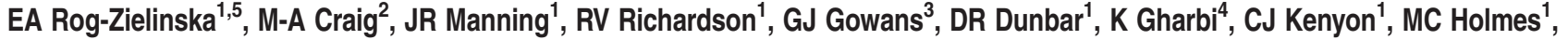 \\ DG Hardie ${ }^{3}$, GL Smith ${ }^{2}$ and KE Chapman ${ }^{*, 1}$
}

Glucocorticoid levels rise dramatically in late gestation to mature foetal organs in readiness for postnatal life. Immature heart function may compromise survival. Cardiomyocyte glucocorticoid receptor (GR) is required for the structural and functional maturation of the foetal heart in vivo, yet the molecular mechanisms are largely unknown. Here we asked if GR activation in foetal cardiomyocytes in vitro elicits similar maturational changes. We show that physiologically relevant glucocorticoid levels improve contractility of primary-mouse-foetal cardiomyocytes, promote Z-disc assembly and the appearance of mature myofibrils, and increase mitochondrial activity. Genes induced in vitro mimic those induced in vivo and include PGC-1 $\alpha$, a critical regulator of cardiac mitochondrial capacity. SiRNA-mediated abrogation of the glucocorticoid induction of PGC-1 $\alpha$ in vitro abolished the effect of glucocorticoid on myofibril structure and mitochondrial oxygen consumption. Using RNA sequencing we identified a number of transcriptional regulators, including PGC-1 $\alpha$, induced as primary targets of GR in foetal cardiomyocytes. These data demonstrate that PGC- $1 \alpha$ is a key mediator of glucocorticoid-induced maturation of foetal cardiomyocyte structure and identify other candidate transcriptional regulators that may play critical roles in the transition of the foetal to neonatal heart.

Cell Death and Differentiation (2015) 22, 1106-1116; doi:10.1038/cdd.2014.181; published online 31 October 2014

Maturation of foetal tissues in readiness for the transition from foetal to postnatal life is dependent on the dramatic rise in glucocorticoid levels shortly before birth. ${ }^{1-3}$ Hence, potentsynthetic glucocorticoids are routinely administered to preterm babies or foetuses at risk of premature birth, to improve neonatal survival. ${ }^{4}$ In addition to the beneficial effects of glucocorticoids on lung maturation, we have recently shown that glucocorticoids are vital to mature foetal-heart structure and function. Endogenous glucocorticoids act via glucocorticoid receptor (GR) in foetal cardiomyocytes/vascular smooth muscle to promote myofibril assembly and organisation, thus advancing systolic function and cardiac ultrastructural organisation in vivo. ${ }^{5}$ These maturational effects are associated with mRNA changes in the foetal heart indicative of improved contractile function, calcium handling and energy metabolism. However, the genes directly under GR control in cardiomyocytes responsible for these vital changes are unknown.

In foetal mice, levels of the endogenous glucocorticoid, corticosterone, are negligible in heart at embryonic day $(E)$ 14.5, but rise rapidly once adrenal corticosterone synthesis begins at $\mathrm{E} 15,{ }^{6}$ peaking at $\mathrm{E} 16.5 .{ }^{5,7}$ Consistent with this, GR only becomes localised to the nucleus in mouse cardiomyocytes at E15.5, suggesting the key events initiated by GR activation occur over $24 \mathrm{~h}$ or less. Although several studies have reported glucocorticoid-induced mRNA changes in $24 \mathrm{~h}$ in primary rodent neonatal cardiomyocytes, foetal cardiomyocytes are less mature than neonatal. ${ }^{8}$ Also, unlike neonatal cardiomyocytes, foetal cardiomyocytes have not had prior exposure to high levels of glucocorticoids in utero, which can alter the response to subsequent glucocorticoid exposure, ${ }^{9}$ itself highly cell and context dependent. ${ }^{10,11}$ Moreover, no previous studies in cardiomyocytes have examined the primary events initiated by GR activation. Here, we used primary-mouse-foetal cardiomyocytes to demonstrate direct actions of glucocorticoids in recapitulating the structural, functional and biochemical consequences of GR activation in vivo. Moreover, we have identified genes directly regulated by GR and show a critical role for induction of the transcriptional coactivator, PGC-1 $a$ in the structural maturation of foetal cardiomyocytes induced by glucocorticoid treatment in vitro.

\section{Results}

Primary mouse foetal cardiomyocytes are glucocorticoid responsive. We first established that mouse foetal cardiomyocytes in culture contain functional GR. Immunofluorescence

${ }^{1}$ Centre for Cardiovascular Science, Queen's Medical Research Institute, University of Edinburgh, Edinburgh, UK; ${ }^{2}$ Institute of Comparative Medicine, Faculty of Veterinary Medicine, University of Glasgow, Glasgow, UK; ${ }^{3}$ Division of Cell Signalling \& Immunology, College of Life Sciences, University of Dundee, Dundee, UK and ${ }^{4}$ Edinburgh Genomics, Ashworth Building, King's Buildings, University of Edinburgh, Edinburgh, UK

${ }^{*}$ Corresponding author: KE Chapman, Centre for Cardiovascular Science, University of Edinburgh, Queen's Medical Research Institute, Edinburgh EH16 4TJ, UK. Tel: +44 (0) 131242 6736; Fax: +44 (0) 131242 6779; E-mail: Karen.Chapman@ed.ac.uk

${ }^{5}$ Current address: National Heart and Lung Institute, Imperial College London, London, UK.

Abbreviations: ANP, atrial natriuretic peptide; $\alpha$-SMA, $\alpha$-smooth muscle actin; $\mathrm{Ca}_{\mathrm{v}} 1.2$, voltage-gated calcium channel; chx, cycloheximide; cort, corticosterone; dex, dexamethasone; DNP, 2,4-dinitrophenol; E, embryonic day; GILZ, glucocorticoid-induced leucine zipper; GO gene ontology; GR, glucocorticoid receptor; hESC human ES cells; MR, mineralocorticoid receptor; MyHC $\alpha$, myosin heavy chain $\alpha$; $\mathrm{NCX} 1, \mathrm{Na}^{+} / \mathrm{Ca}^{2+}$ exchanger; OCR, oxygen consumption rate; PGC- $1 \alpha$, PPAR $\gamma$ coactivator receptor $\alpha$; RNAseq, RNA sequencing; ROS, reactive oxygen species; RU486, mifepristone (RU38486); RyR2, ryanodine receptor-2; SERCA2, sarco/endoplasmic reticulum Ca ${ }^{2+}$ ATP-ase; SIc, solute carrier; TBP, TATA binding protein

Received 31.3.14; revised 08.9.14; accepted 22.9.14; Edited by JA Cidlowski; published online 31.10.14 
confirmed nuclear translocation of GR within $1 \mathrm{~h}$ of addition of physiological glucocorticoid, corticosterone, or the potentsynthetic glucocorticoid, dexamethasone, to cardiomyocytes isolated from E14.5-E16.5 C57BL/6 mouse foetal hearts (Supplementary Figure 1B). Levels of Dusp1 and Fkbp5 mRNAs, known GR target genes ${ }^{12,13}$ were increased following glucocorticoid treatment (Supplementary Figure 1C).

Corticosterone promotes sarcomeric organisation and myofibril assembly in foetal cardiomyocytes. Having confirmed a response to glucocorticoids, we asked whether glucocorticoid treatment in vitro can mimic the improvement in myofibrillar structure evoked by GR activation in vivo in cardiomyocytes. ${ }^{5}$ Primary foetal cardiomyocytes were treated with $100 \mathrm{nM}$ corticosterone, approximating levels in the wild-type late gestation (E16.5-E17.5) foetal heart, for $24 \mathrm{~h}$. As well as inducing the formation of troponin T-associated $a$-smooth muscle actin stress fibres in primary foetal cardiomyocytes (Supplementary Figure 1D), corticosterone dramatically altered myofibril organisation, visualised by staining of $a$-actinin (Figure 1a), a constituent of myofibrillar Z-discs. Though Z-disc structures were observed in untreated cells, they became better defined, aligned, and regularly distributed throughout cardiomyocytes following the corticosterone treatment (Figure 1a). The overall appearance of myofibrillar structure was improved, and the sarcomere length (measured as the distance between neighbouring Z-discs) and Z-disc width were increased following the corticosterone treatment (Figure 1b). Pre-treatment with the GR antagonist, RU38486 (RU486), abolished the effect of corticosterone on myofibrillar structure, demonstrating its dependence on GR (Figures 1a and b).

Transmission electron microscopy of sections through primary foetal cardiomyocytes showed a striking increase in contractile fibres in corticosterone-treated cardiomyocytes with clearly delineated myofibrils often associated with welldefined Z-discs (Figure 1c). In contrast, very few Z-discs were apparent in untreated cells and although some fibrillar material was present, it was predominantly disorganised and scattered throughout the cell.

\section{Corticosterone improves contractility of foetal cardio-} myocytes. We next asked, whether the improved myofibrillar structure is associated with improved function by measuring the effect of corticosterone on the contractile properties of primary foetal cardiomyocytes using soft-video edge detection. Treatment with $100 \mathrm{nM}$ corticosterone for $24 \mathrm{~h}$ did not affect the frequency of spontaneous contractions (Figure $2 \mathrm{a}$; control $35.1 \pm 1.3$ beats/min versus corticosterone $39.0 \pm 1.8$ beats/min; $n=38$ cells) but markedly increased contraction amplitude (Figures 2b and c). Corticosterone also decreased contraction and relaxation times (bottom-to-peak and peakto-bottom time, respectively; Figure 2d) and improved the relaxation kinetics, measured as the time taken to reach $90 \%$ relaxation (Figure 2e). Thus, structural improvements elicited by corticosterone are associated with improved contractile function.

Glucocorticoids via GR regulate candidate gene expression in cardiomyocytes. To establish that the transcriptional
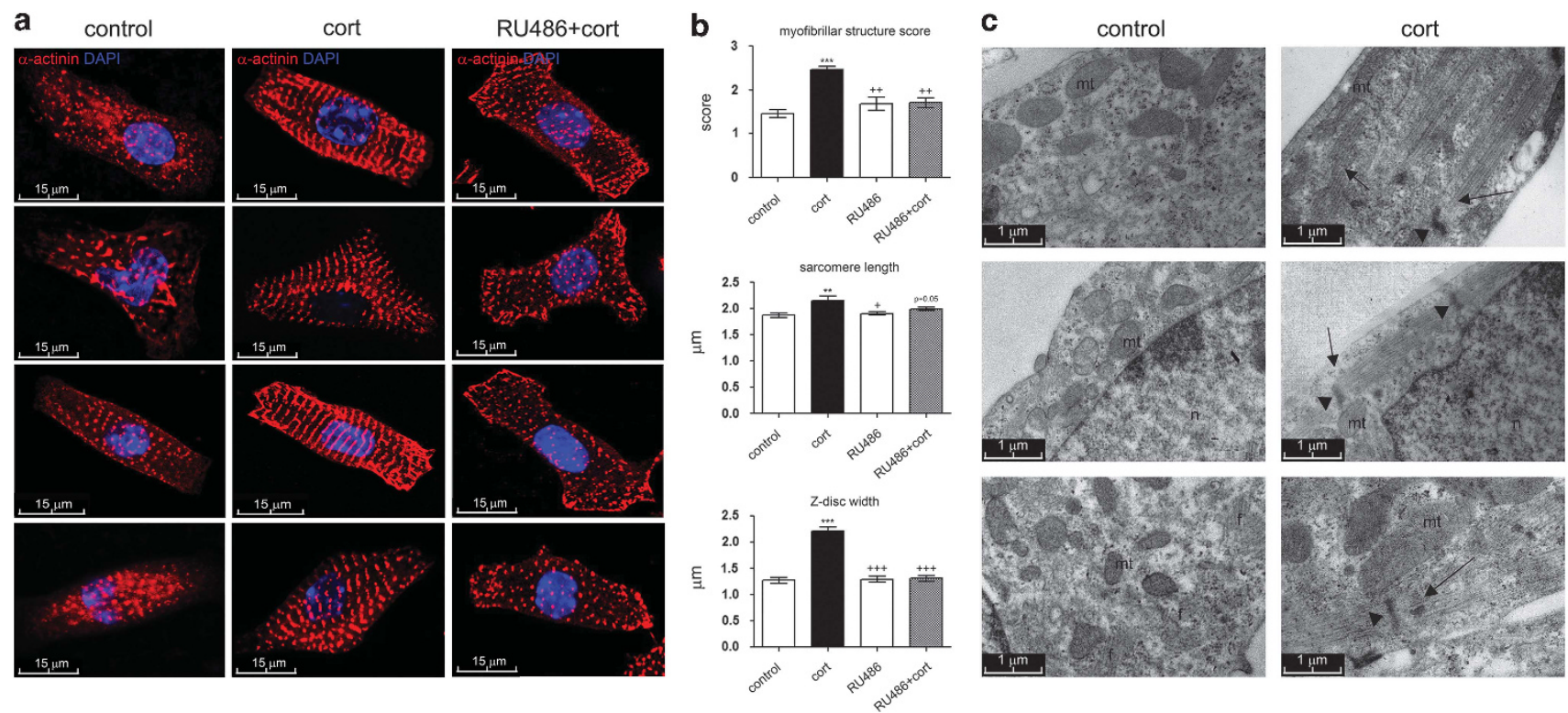

Figure 1 Corticosterone promotes myofibril maturation in foetal cardiomyocytes in a GR-dependent manner. (a) Representative images of control (untreated) primary foetal C57BL/6 cardiomyocytes (left panels), or following $100 \mathrm{nM}$ corticosterone (cort) for $24 \mathrm{~h}$ (centre panels). To block GR-mediated effects, cells were pre-treated with $1 \mu \mathrm{M}$ RU38486 (RU486) for $30 \mathrm{~min}$ prior to addition of $100 \mathrm{nM}$ corticosterone for $24 \mathrm{~h}$ (RU486+cort; right panels). Cells were stained with $\alpha$-actinin (red, Z-discs) and DAPI (blue, nuclei). (b) Quantification of the effect of $100 \mathrm{nM}$ cort on myofibrillar structure (top graph, see Materials and Methods for details of the scoring system), sarcomere length (middle graph), and Z-structure/Z-disc width (bottom graph). Data were analysed by one-way ANOVA with Bonferroni's post-hoc test; ${ }^{* *} P<0.01,{ }^{* * *} P<0.001$ versus control; ${ }^{{ }^{*}} P<0.05$, ${ }^{++} P<0.01,{ }^{++} P<0.001$ versus cort; $n=50-80$ replicates over three independent experiments. (c) Representative transmission electron micrographs of sections of control primary foetal C57BL/6 mouse cardiomyocytes (left panels), or following $100 \mathrm{nM}$ corticosterone (cort) for $24 \mathrm{~h}$ (right panels); arrows, myofibrils; arrowheads, $\mathrm{Z}$ discs; $\mathrm{mt}$, mitochondria; f, fibres; $\mathrm{n}$, nuclei. Images representative of $n=10$ cells 
a

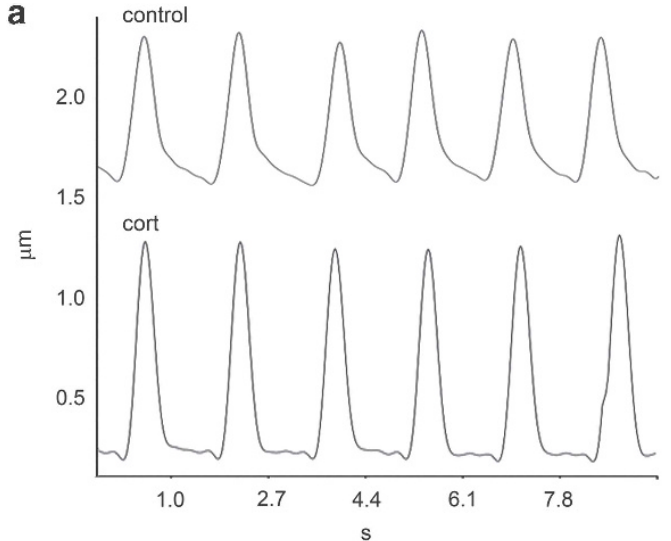

b

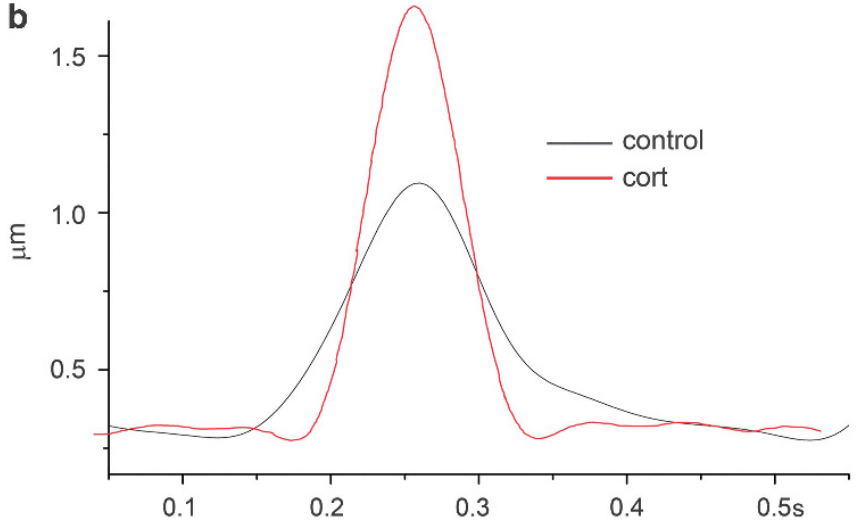

c

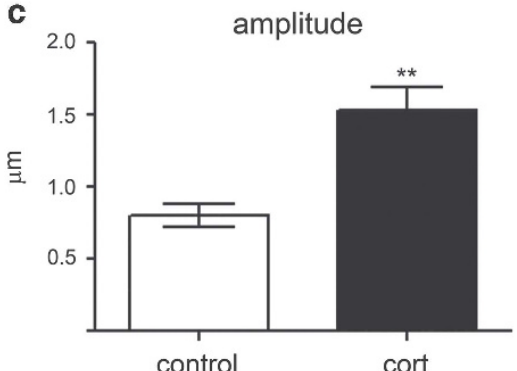

d

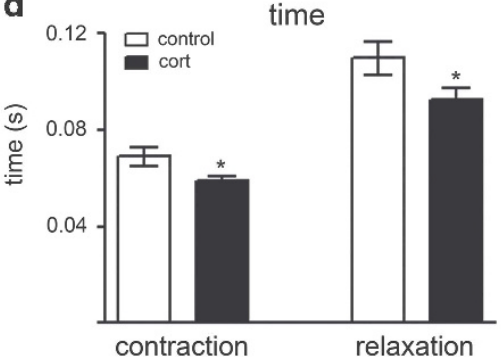

e

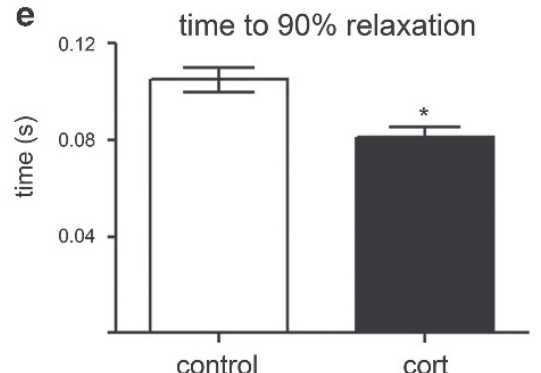

Figure 2 Corticosterone treatment improves the contraction-relaxation of foetal cardiomyocytes. Cells were treated with $100 \mathrm{nM}$ corticosterone for $24 \mathrm{~h}$ prior to edgedetection analysis. (a, b) Representative edge-detection traces showing single contraction (upwards)/relaxation (downwards) events for untreated (control/black) and corticosterone-treated (cort/red) cells. Corticosterone increased the amplitude of contraction (c), measured as the distance travelled by the cardiomyocyte edge during the shortening phase, and (d) decreased the time of contraction and relaxation as well as (e) decreased time taken to reach $90 \%$ relaxation. Data were analysed by Student's $t$-test; ${ }^{\star} P<0.05,{ }^{* *} P<0.01 ; n=38$ cells

response of primary foetal cardiomyocytes to glucocorticoids resembles that of the foetal heart, we measured mRNAs that we have previously shown to be altered in heart by glucocorticoid action in vivo. ${ }^{5}$ Tsc22d3 (encoding glucocorticoidinduced leucine zipper) represents a classical glucocorticoidregulated gene, with Myh6 (encoding myosin heavy chain- $a$; $\mathrm{MyHCa}$ ) and Ppargc1a (encoding PPARy coactivator-1a; PGC-1a) representative of structural and metabolic genes, respectively. Nppa (encoding atrial natriuretic peptide) is known to be glucocorticoid regulated in neonatal rat cardiomyocytes. 8,14 Corticosterone activates GR, but can also activate mineralocorticoid receptor (MR) in the absence of $11 \beta$-hydroxysteroid dehydrogenase-2..$^{15,16}$ We therefore compared the effect of corticosterone with that of dexamethasone, which poorly activates MR. ${ }^{16}$ Dexamethasone induced all four mRNAs in a dose-dependent manner over $24 \mathrm{~h}$ (Figures 3a-d). Similarly, 100-200 nM corticosterone, approximating concentrations in the late-gestation mouse heart, increased Tsc22d3, Nppa, and Ppargc1a mRNA levels (Figures 3e-h). The modest increase in Myh6 mRNA levels with $100 \mathrm{nM}$ corticosterone was not observed with the higher dose of $200 \mathrm{nM}$ corticosterone. Glucocorticoid treatment also induced genes involved in calcium handling: Cacna1c, Ryr2, Atp2a2, and Slc8a1, encoding respectively, $\mathrm{Ca}_{\mathrm{v}} 1.2$ (voltagegated $\mathrm{Ca}^{2+}$ channel), ryanodine receptor-2, SERCA2a (sarco/endoplasmic reticulum $\mathrm{Ca}^{2+}$ ATP-ase $2 \mathrm{a}$ ) and $\mathrm{NCX} 1$ $\left(\mathrm{Na}^{+} / \mathrm{Ca}^{2+}\right.$ exchanger; Supplementary Figures $2 \mathrm{~A}$ and $\left.\mathrm{D}\right)$, consistent with effects of endogenous GR activation in foetal heart in vivo. ${ }^{5}$
RU486 antagonism of GR blocked the glucocorticoid induction of Tsc22d3, Myh6, Nppa, and Ppargc1a mRNAs (Figure 4) whereas the MR antagonist spironolactone had no effect (Supplementary Figures $2 \mathrm{E}$ and $\mathrm{H}$ ). Similarly, siRNA mediated knock-down of GR $(80 \%$ and $35 \%$ reduction in GR mRNA and protein levels, respectively; Supplementary Figures $3 \mathrm{~A}$ and $\mathrm{B}$ ) attenuated the dexamethasone induction of these mRNAs (Figure 4) with little or no effect of scrambled siRNA on dexamethasone-induced transcriptional responses (Supplementary Figure 3C). These experiments confirm GR as a crucial mediator of the transcriptional responses to glucocorticoids in foetal cardiomyocytes. To examine direct regulation by GR, cycloheximide was administered prior to dexamethasone, to block new protein synthesis. Glucocorticoid-induction of Tsc22d3 and Ppargc1a mRNA was maintained (and increased in the case of Ppargc1a) with cycloheximide, suggesting these genes are direct targets of GR in cardiomyocytes (Figures $4 a$ and d). In contrast, glucocorticoid induction of Myh6 and Nppa mRNAs was abolished by cycloheximide demonstrating this regulation depends on new protein synthesis (Figures $4 b$ and $c$ ).

RNAseq analysis reveals potential primary glucocorticoid targets in cardiomyocytes. The above experiments suggest GR initiates a transcriptional cascade in foetal cardiomyocytes, in which master regulators (such as Tsc22d3 and Ppargc1a) are induced to establish the maturational programme. To explore the extent of the glucocorticoid-induced programme and to identify potential 


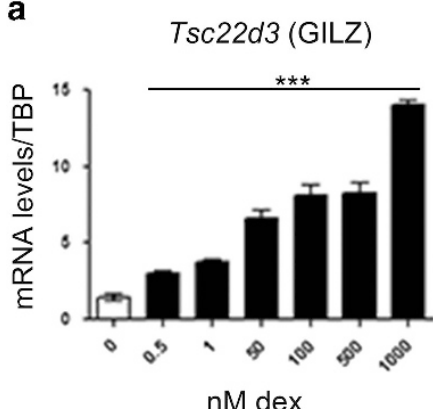

e

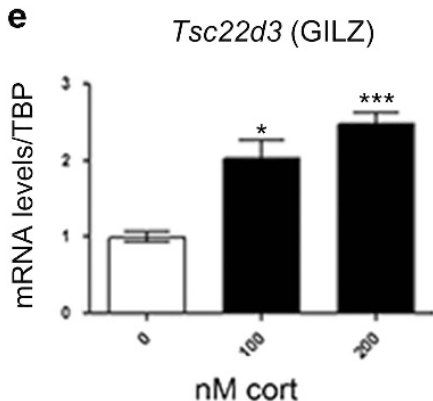

b

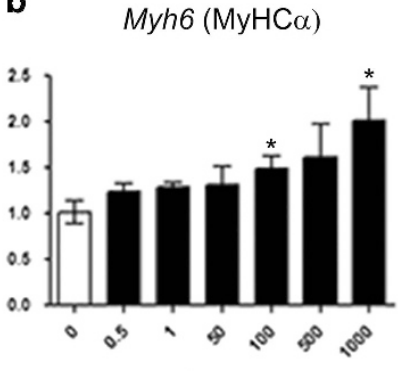

nM dex

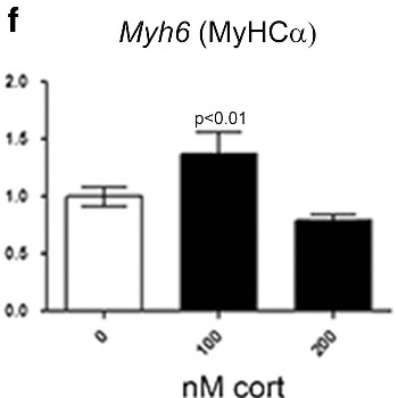

C

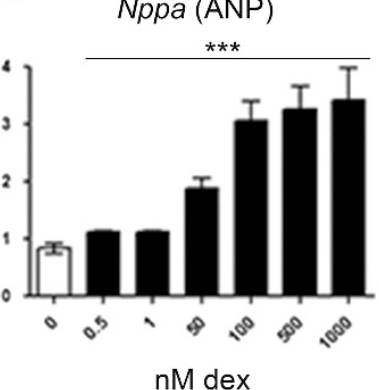

g

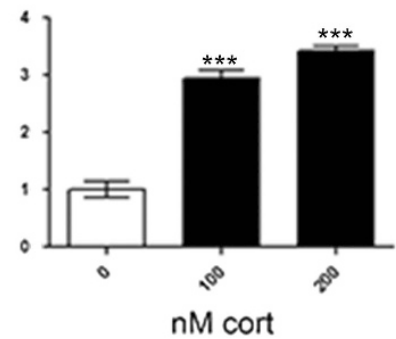

d

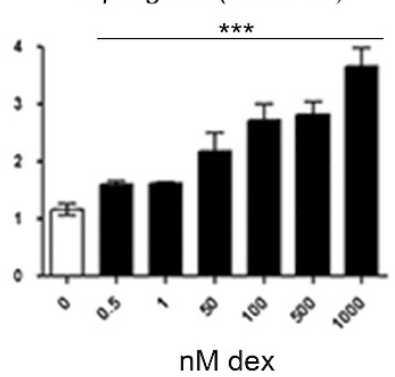

h Ppargc1a (PGC-1 $\alpha)$

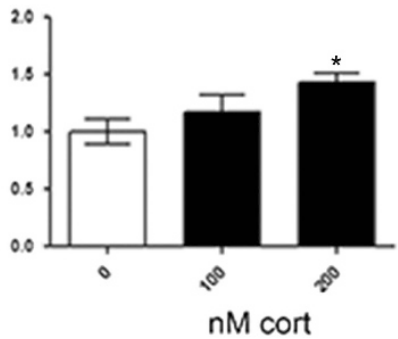

Figure 3 Glucocorticoid treatment of primary foetal cardiomyocytes dose-dependently replicates in vivo regulation of cardiac gene expression by glucocorticoid action. Treatment of primary foetal C57BL/6 cardiomyocytes for $24 \mathrm{~h}$ with dexamethasone (dex) (a-d) or corticosterone (cort) (e-h) dose-dependently increased levels of mRNA encoding glucocorticoid-induced leucine zipper (GILZ), MyHC $\alpha$, atrial natriuretic peptide (ANP) and PGC-1 $\alpha$. Data were analysed by one-way ANOVA with Bonferroni post-hoc test; ${ }^{\star} P<0.05,{ }^{* \star} P<0.01,{ }^{* \star *} P<0.001 ; n=5$ replicates over two independent experiments

master regulators and primary target genes of GR in foetal heart, next generation RNA sequencing (RNAseq) was performed on primary foetal cardiomyocytes following treatment with $100 \mathrm{nM}$ dexamethasone for $2 \mathrm{~h}$ in the presence of cycloheximide. Controls were treated with cycloheximide alone. A total of 613 transcripts covering 564 genes were differentially expressed (adjusted $P<0.05$ ) in glucocorticoidtreated cardiomyocytes, with 469 transcripts increased and 144 decreased. As expected, the induced genes included Ppargc1a and Tsc22d3 (Table 1). Gene set enrichment analysis with gene ontology (GO) terms revealed sequencespecific DNA binding proteins with transcription factor activity, and sequence-specific DNA binding proteins to be the two groups of most over-represented terms affecting molecular function, representing $\sim 9 \%$ of differentially expressed genes (Table 1; see Supplementary Table 1 for the full list). These include regulators of key pathways including development and growth (Notch1, Myc, Wt1, Hes1), circadian rhythm (Per1, Nr1d1), metabolism (Cebpb, Ppara), and hypoxia (Hif3a, Epas1), several of which are known GR targets in other cell types (e.g., Hes1, Notch1, Per1, Ppara ${ }^{17-20}$ ). $\mathrm{Nr3c1}$, encoding GR itself, was repressed, though $\mathrm{Nr} 3 c 2$ (encoding MR) was unaffected by dexamethasone. NrOb2, encoding small heterodimer partner (SHP), a repressor of nuclear receptor function and regulator of both PGC-1 and GR activity, ${ }^{21}$ was also included in this group. Several induced genes encode factors implicated in early cardiac development, including Klf2 and Notch1. Our data suggest they may also be induced by glucocorticoid to play a later role in cardiac maturation. Although Klf2 mRNA was unaltered in hearts of $\mathrm{E} 17.5 \mathrm{GR}^{-1-}$ foetuses, ${ }^{5} \mathrm{Klf2}$ might be transiently induced in the wild-type heart as corticosterone levels increase at E15.5, with subsequent negative feedback returning levels to basal by E17.5. Such temporary increases in key developmental or transcriptional regulators can lead to permanent changes in cellular transcriptional programmes, setting the cell on the path to terminal differentiation. ${ }^{22}$ It is also possible these effects on expression of developmental regulators relates to the in vitro conditions used here.

Other transcriptional regulators, which themselves are not DNA binding proteins, were differentially expressed. These include reciprocal regulation of Ppargc1a (increased twofold) and Ppargc1b (decreased to almost the same extent). Current evidence suggests PGC- $1 \beta$ plays a redundant role in foetal heart maturation. ${ }^{23}$ However, PGC-1 $\beta$ expression declines as PGC-1a expression increases during cardiomyocyte differentiation of human ES cells (hESC), ${ }^{24}$ consistent with our data. Other repressed genes include Bmp4, Hey1, and Efna1, encoding key regulators of early cardiac differentiation, ${ }^{25-29}$ in accordance with the maturational effects of glucocorticoids on foetal cardiomyocytes.

Other differentially expressed genes include cell surface growth factor or neurotransmitter receptors as well as several members of the voltage-gated potassium channel family (e.g., Kcna5, Kcnk1, Kcne4, Kcnk5) and subunits of the ENaC epithelial sodium channel. Members of the voltage-gated potassium channel family have previously been identified as glucocorticoid-regulated genes, ${ }^{30-32}$ supporting their identification here as primary targets of GR in foetal cardiomyocytes. Several members of the Slc family of solute transporters were differentially expressed suggesting altered transport of small molecules across membranes. These include four members of the SIC25 family of mitochondrial carriers, S/c25a25, Slc25a33, SIc25a18, and SIC25a30, two of which transport 


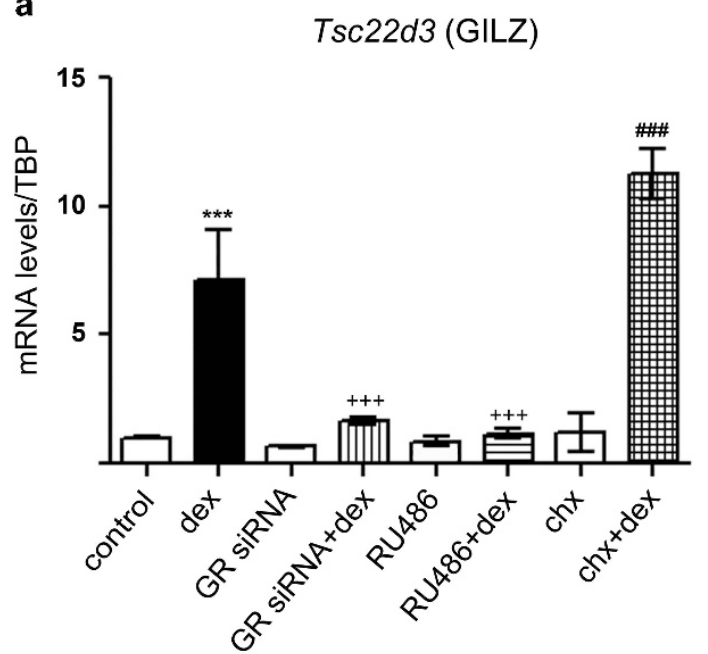

C

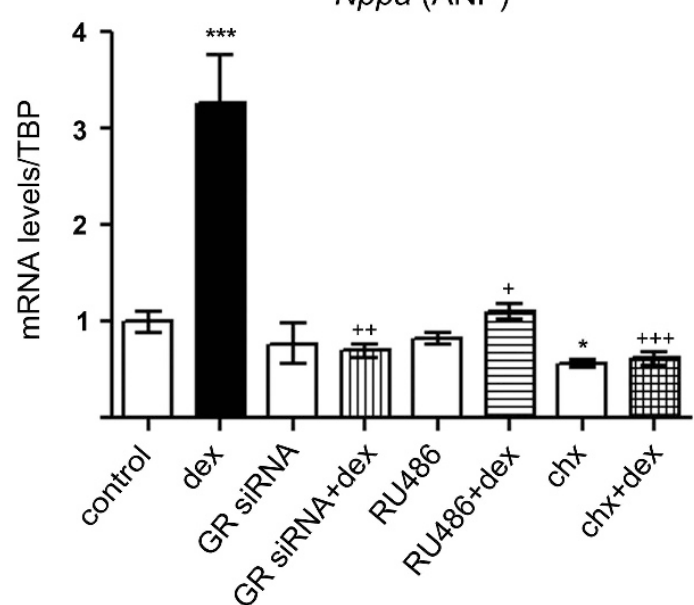

b

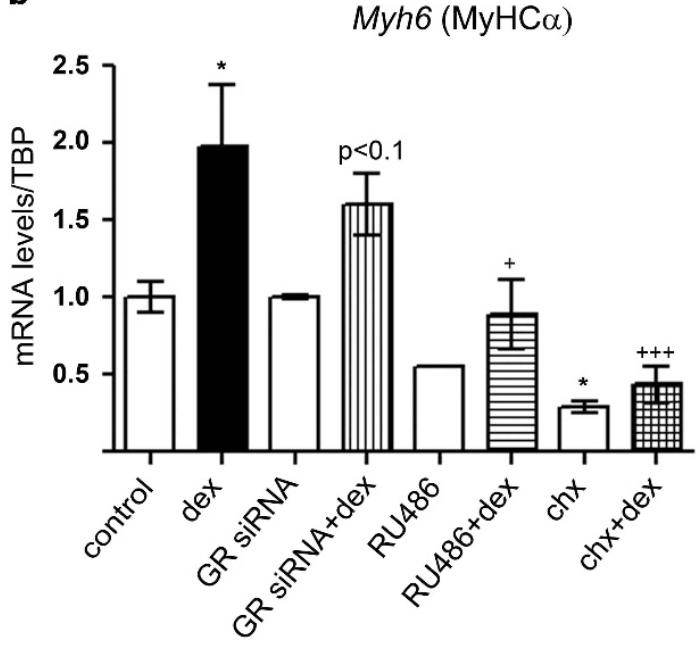

d

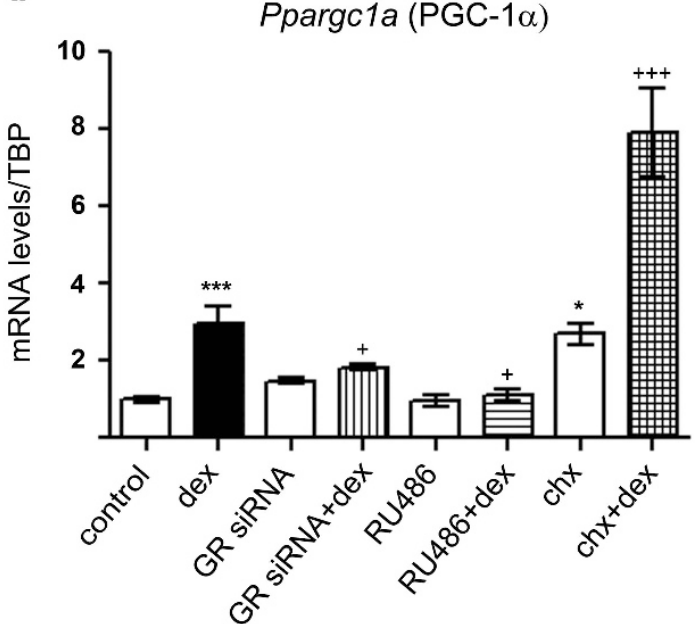

Figure 4 Glucocorticoids act via GR to exert transcriptional effects on primary-mouse-foetal cardiomyocytes. GR siRNA or pretreatment with RU486 (10 $\mu \mathrm{M}, 30$ min) blocked or attenuated the dexamethasone ( $1 \mu \mathrm{M}, 24 \mathrm{~h}$ ) induction of mRNAs encoding GILZ (a), ANP (b), MyHC $\alpha$ (c) and PGC-1 $\alpha$ (d). Cycloheximide (CHX, $10 \mu \mathrm{M}, 30 \mathrm{~min})$ pretreatment blocked the glucocorticoid induction of MyHC $\alpha$ and ANP, but not GILZ or PGC-1 $\alpha$. Data were analysed by two-way ANOVA with Bonferroni multiple comparisons post-hoc test; ${ }^{\star} P<0.05,{ }^{* \star} P<0.01,{ }^{* \star} P<0.001$ versus untreated; ${ }^{+} P<0.05,{ }^{++} P<0.01,{ }^{++} P<0.001$ versus dex; $n=4$ replicates. Statistical significance versus dex is only indicated for dexamethasone-treated groups

nucleotides. Thus, glucocorticoids directly affect some aspects of mitochondrial function whereas other may be secondary to induction of "master regulators" such as PGC-1a.

PGC-1a mediates the effects of glucocorticoids on myofibrillar structure and oxygen consumption of cardiomyocytes. We validated PGC-1a as an early target of glucocorticoid action in foetal cardiomyocytes by confirming dexamethasone induction of Ppargc1a mRNA within $2 \mathrm{~h}$ as well as $8 \mathrm{~h}$ of dexamethasone addition. Although steady-state Ppargc1a mRNA levels increased following addition of cycloheximide (suggesting rapid turnover of Ppargc1a mRNA), dexamethasone further increased Ppargc1a mRNA levels, above those with cycloheximide alone (Supplementary Figures 3D and E), consistent with Ppargc1a being a direct target of GR. In vivo, Ppargc1a mRNA levels are reduced in hearts of $\mathrm{GR}^{-1-}$ mice ${ }^{5}$ and like $\mathrm{GR}^{-/-}$foetuses, mice lacking PGC-1 $a$ and PGC-1 $a$ show profound defects in foetal cardiac maturation with functionally immature hearts and persistence of a foetal-gene expression pattern, including reduced expression of Atp2a2 and Myh6. ${ }^{23}$ Ppargc1a is normally induced at $\mathrm{E} 15.5^{23}$ co-incident with the rise in cardiac corticosterone levels, which are negligible at E14.5. ${ }^{5}$ To test whether glucocorticoids can induce Ppargc1a in vivo, dexamethasone was injected into pregnant dams at E14.5. Within $6 \mathrm{~h}$, steady-state levels of Ppargc1a mRNA were increased in foetal hearts, as were levels of Fkbp5 mRNA, a well-known GR target (Figures $5 a$ and b), confirming glucocorticoid regulation in vivo. To determine whether PGC-1a induction is critical for glucocorticoids to elicit foetal cardiomyocyte maturation, PGC-1a siRNA was used to reduce Ppargc1a mRNA levels $\sim 60 \%$, abolishing the normal increase in Ppargc1a mRNA levels following glucocorticoid treatment (Supplementary Figure 4A). This reduction of Ppargc1a mRNA in glucocorticoid-treated cardiomyocytes, to reach the same level as in untreated cells, markedly 
Table 1 Differentially expressed genes were subject to gene set enrichment analysis with gene ontology terms affecting molecular function

\begin{tabular}{|c|c|c|c|c|}
\hline$P$-value & $\begin{array}{l}\text { Expected } \\
\text { count }\end{array}$ & Count & Size & Genes (fold-change) \\
\hline \multicolumn{5}{|c|}{ GO:0003700: sequence-specific DNA binding transcription factor activity } \\
\hline $1.392 \times 10^{-6}$ & 14.523 & 35 & 393 & $\begin{array}{l}\text { Klf5 (3.07), Runx1t1 (2.01), Cebpb (3.13), Arid3a (-1.67), Elf3 (-4.92), Epas1 (1.51), } \\
\text { Erf (3.45), Tsc22d3 (2.11), Nr3c1 (-1.47), Gsc (18.48), Hand2 (1.58), Hes1 (-3.73), } \\
\text { Hey1 (-3.38), Hix (3.43), Id3 (-2.01), Irf1 (-1.61), Klf2 (1.72), Mafb (-3.21), Lhx6 (7.40), } \\
\text { Mycl1 (6.53), Aff1 (2.15), Mnt (-1.85), Myc (2.09), Nfe2l3 (-1.68), Mycn (-1.47), Notch1 } \\
\text { (2.07), Pitx3 (38.36), Ppara (2.93), Prox1 (-1.72), Six1 (2.56), Sox12 (-1.55), Sox4 (1.97), } \\
\text { Bhlhe40 (-1.99), Tfdp2 (2.88), Csrnp1 (2.22), Hlf (2.08), Nr1d1 (-1.62), Rarb (-1.62), } \\
\text { Vdr (4.02), Wt1 (2.10), Tgif2 (-1.68), Grhl3 (1.81), Zbtb16 (61.17), Nrob2 (1.62), Hif3a (7.36), } \\
\text { Heyl (-2.01), Foxo3 (2.68), Elf4 (-1.81), Klf15 (3.07), Tcfap4 (-1.70), Glis2 (-1.91) }\end{array}$ \\
\hline
\end{tabular}

GO:0043565: sequence-specific DNA binding $2.48 \times 10^{-5} \quad 17.238 \quad 36 \quad 458$
Cebpb (3.13), Elf3 (-4.92), Epas1 (1.51), Erf (3.45), Nr3c1 (-1.47), Gsc (18.48), Hand2 (1.58), Hes1 (-3.73), Hey1 (-3.38), HIx (3.43), Irf1 (-1.61), Klf2 (1.72), Mafb (-3.21), Lhx6 (7.40), Myc (2.09), Nfe2l3 (-1.68), Notch1 (2.07), Per1 (6.08), Pitx3 (38.36), Ppara (2.93), Prox1 (-1.72), Scx (-1.61), Six1 (2.56), Sox12 (-1.55), Sox4 (1.97), Hlf (2.08), Nr1d1 (-1.62), Rarb (-1.62), Vdr (4.02),Wt1 (2.10), Tgif2 (-1.68), Heyl (-2.01), Foxo3 (2.68), Elf4 (-1.81), Ctcfl (2.13), Tcfap4 $(-1.70)$

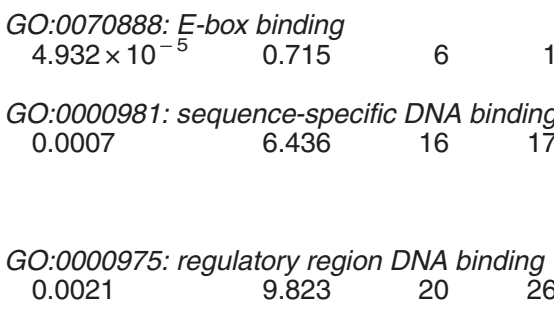

GO:0070888: E-box binding

GO:0001077: RNA polymerase II core promoter proximal region sequence-specific DNA binding transcription factor

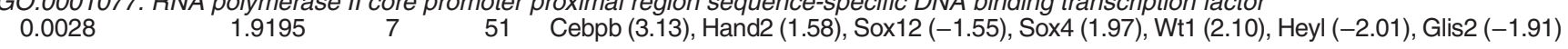

GO:0000988: protein binding transcription factor activity

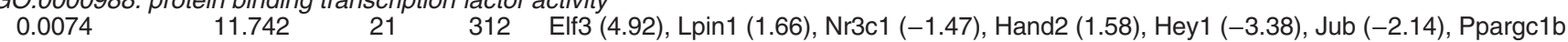
(-1.85), Per1 (6.08), Per2 (1.95), Ppargc1a (1.97), Prox1 (-1.72), Sox12 (-1.55), Sox4 (1.97), Bhlhe40 (-1.99), NrOb2 (1.62), Irf2bp2 (1.88), Heyl (-2.01), Cited4 (-1.58), Sertad2 (-1.62), Med26 (2.46), Tbl1xr1 (1.83)

$\begin{array}{cccc}\text { GO:0008134: transcription factor binding } & \\ 0.0153 & 13.361 & 22 & 355\end{array}$

GO:0003712: transcription cofactor activity $\begin{array}{llll}0.0427 & 10.764 & 17 & 286\end{array}$

355 Cebpb (3.13), Epas1 (1.51), Lpin1 (1.66), Tsc22d3 (2.11), Nr3c1 (-1.47), Hand2 (1.58), Hes1 (-3.73), Id3 (-2.01), Id4 (2.21), Mafb (-3.21), Myc (2.09), Nab2 (-1.97), Nfkbia (3.04), Ppara (2.93), Ppargc1a (1.97), Scx (-1.61), Bhlhe40 (-1.99), Tfdp2 (2.88), Vdr (4.02), NrOb2 (1.62), Foxo3 (2.68), Tob2 (5.03)

Elf3 (4.92), Lpin1 (1.66), Nr3c1 (-1.47), Hand2 (1.58), Jub (-2.14), Ppargc1b (-1.85), Ppargc1a (1.97), Prox1 (-1.72), Sox12 (-1.55), Sox4 (1.97), Nr0b2 (1.62), Irf2bp2 (1.88), Heyl (-2.01), Cited4 (-1.58), Sertad2 (-1.62), Med26 (2.46), Tbl1xr1 (1.83)
\end{abstract}

GO terms are indicated, with expected and actual gene counts and $P$-value. Differentially expressed genes are listed with fold-change (dex/control; repression shown as a negative fold-change) indicated in brackets

attenuated the effect of corticosterone on myofibrillar structure, sarcomere length and Z-disc width (Figure 6). In contrast, PGC-1a knock-down had no significant effect on glucocorticoid induction of Tsc22d3, Nppa, or Myh6 (Supplementary Figure 3C), nor, importantly, did it affect Nr3c1 (GR) mRNA or protein levels (Supplementary Figure 3B).

The GR-mediated induction of PGC-1a increases oxygen consumption rate in primary foetal cardiomyocytes.

The known role of PGC-1a in mitochondrial gene expression $^{33}$ suggested that glucocorticoids promote mitochondrial function and/or capacity in foetal cardiomyocytes. To test this, the oxygen consumption rate (OCR) was measured following $100 \mathrm{nM}$ corticosterone treatment for $24 \mathrm{~h}$. OCR was higher in corticosterone-treated cells, an effect attenuated by RU486 (Figure 7a) indicating GR activation increases cellular respiration. Knock-down of PGC-1a eliminated the effect of corticosterone on OCR but had no effect in its absence (Figure $7 \mathrm{~b}$ ), demonstrating that the glucocorticoid-mediated promotion of mitochondrial function as well as cardiomyocyte structure depends upon PGC-1 1 induction. Corticosterone also enhanced the mitochondrial capacity of foetal cardiomyocytes as shown by a greater increase in OCR following addition of 2,4dinitrophenol to uncouple mitochondrial respiration from ATP synthesis (Supplementary Figure 5). 


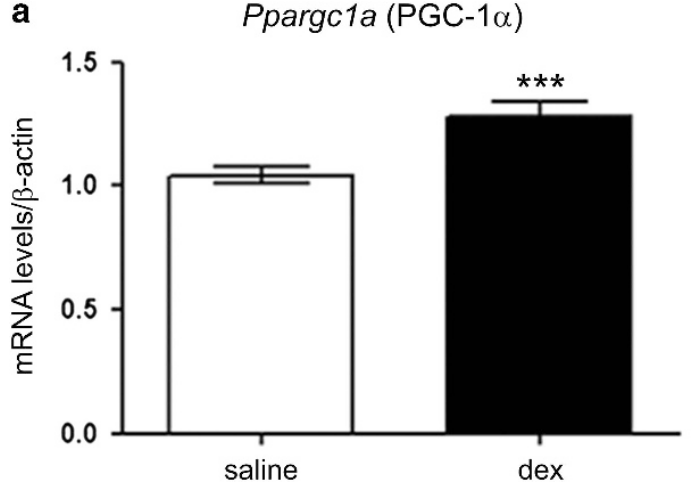

b

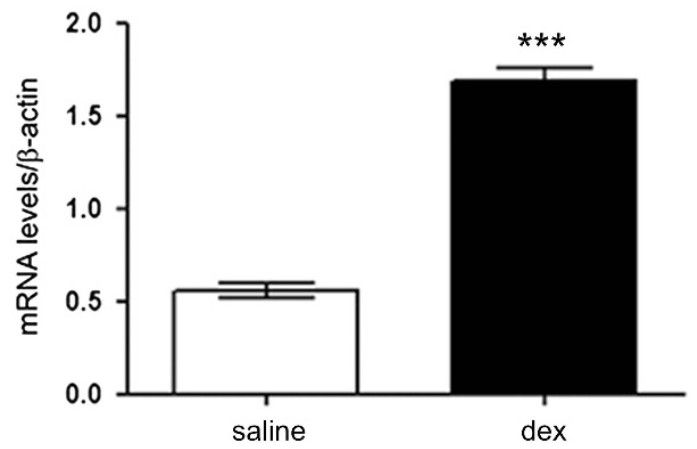

Figure 5 Dexamethasone increases steady-state levels of Ppargc1a (PGC-1 $\alpha$ ) and Fkbp5 mRNA after $6 \mathrm{~h}$ in E14.5 foetal heart. Dexamethasone (500 $\mu \mathrm{g} / \mathrm{kg}$ body weight) was administered to pregnant mothers by peritoneal injection at E14.6. Foetal tissues were collected after $6 \mathrm{~h}$. Data were analysed by Student's $t$-test; ${ }^{* \star \star} P<0.001 ; n=22$ foetuses (from six pregnant dams per group)

control
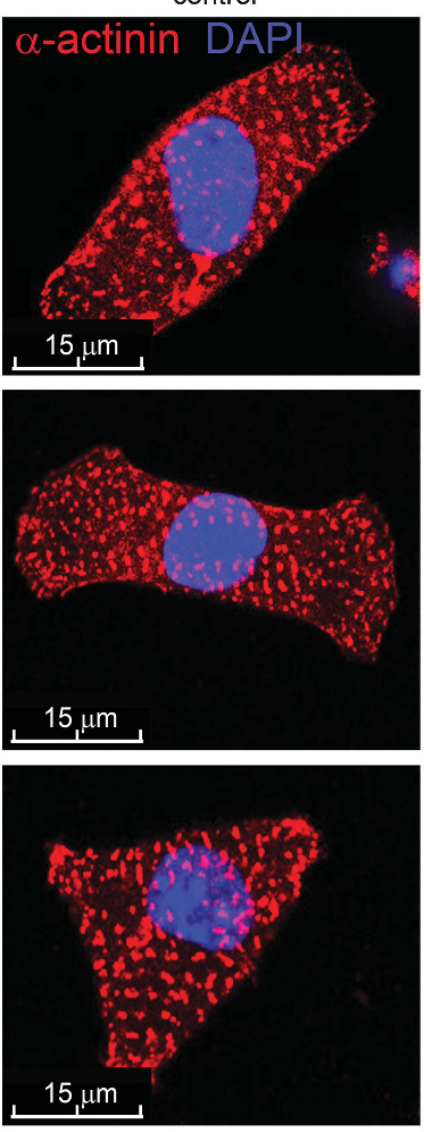

cort
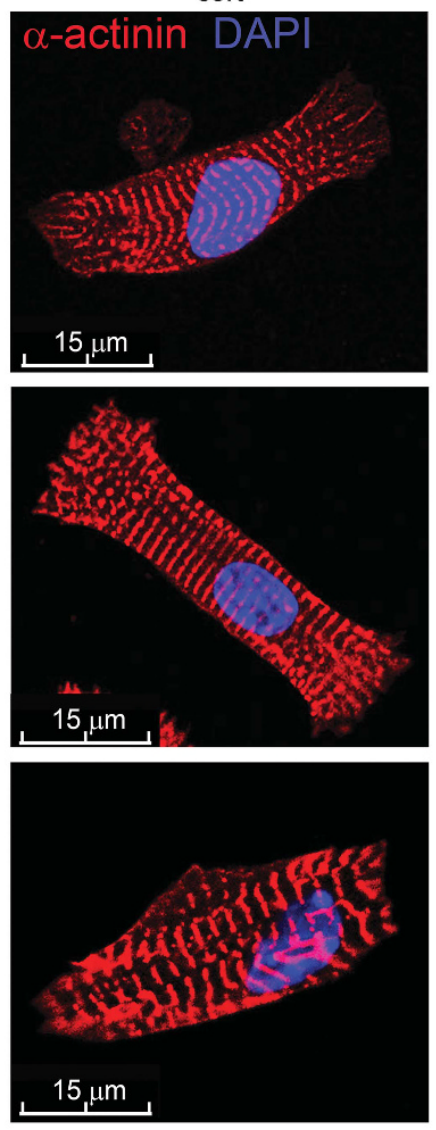

PGC-1 $\alpha$ siRNA+cort
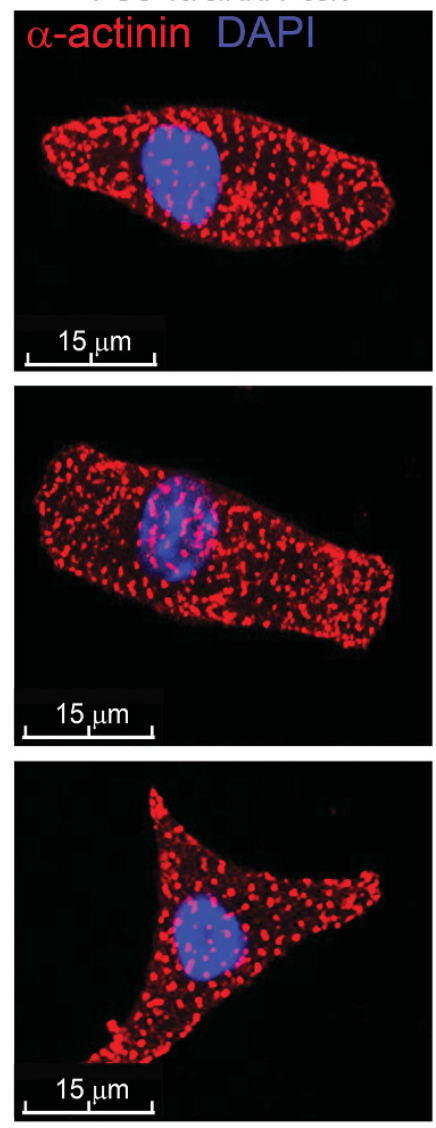

myofibrillar structure score

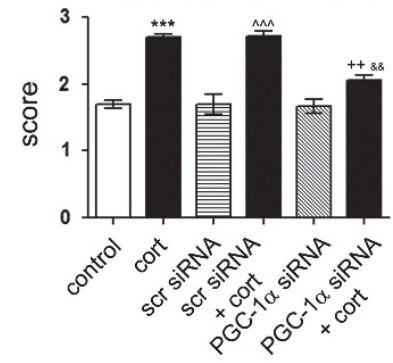

sarcomere length
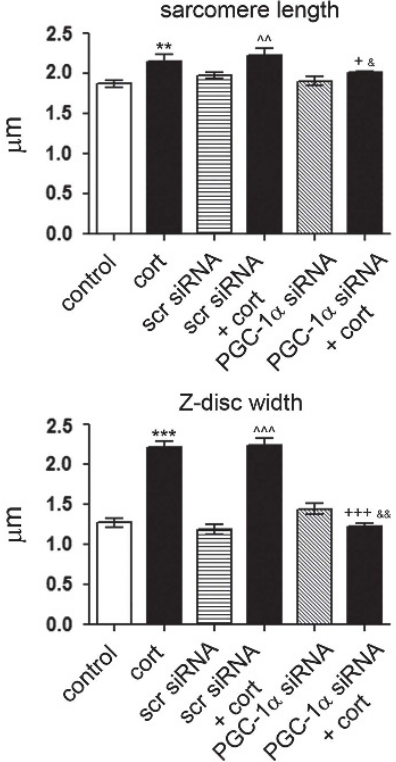

Figure 6 Corticosterone-induced maturation of myofibril structure is abrogated by PGC-1 $\alpha$ knock-down. Cells were untreated (control; left panels) or treated with $100 \mathrm{nM}$ corticosterone for $24 \mathrm{~h}$ (cort; centre panels). To block PGC-1 $\alpha$-mediated effects, cells were transfected with PGC-1 $\alpha$ siRNA $40 \mathrm{~h}$ prior to glucocorticoid treatment (right panels). Cells were fixed and stained for $\alpha$-actinin (red). DAPI (blue) was used as a nuclear counterstain. Images representative of $n=25-120$ cells. Images were also scored for myofibrillar structure (as described in Materials and Methods). PGC-1 $\alpha$ knock-down abrogated corticosterone induced increases in myofibrillar structure score (top graph), sarcomere length (middle graph) and Z-disc width (bottom graph). Data were analysed by one-way ANOVA with Bonferroni's post-hoc test; ${ }^{+/ \&} P<0.05$, ${ }^{* * /++1} / M^{\& \&} P<0.01,{ }^{* \star * /+++/ M M} P<0.001 ;{ }^{*}$ versus untreated control, ${ }^{+}$versus dex, ${ }^{\wedge}$ versus scambled PGC-1 $\alpha$ siRNA, and versus PGC-1 $\alpha$ siRNA; $n=25-120$ replicates over two independent experiments 
a

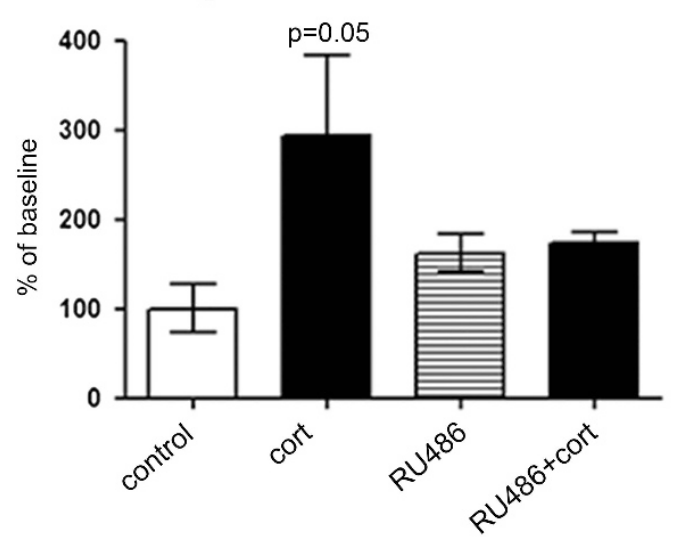

b $\mathrm{O}_{2}$ consumption (pmoles/min/cell)

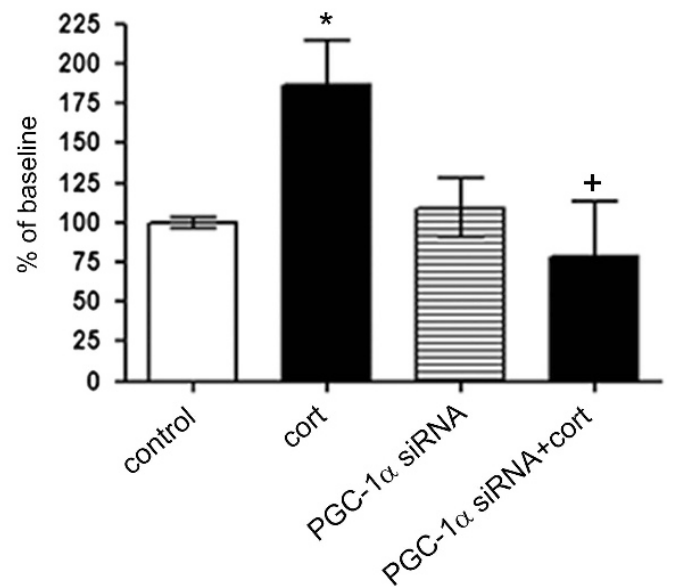

Figure 7 Glucocorticoids act via GR and PGC-1 $\alpha$ to increase mitochondrial respiration in primary foetal cardiomyocytes. Real-time oxygen consumption rate (OCR) was measured in untreated (control) foetal cardiomyocytes or following treatment with $100 \mathrm{nM}$ corticosterone for $24 \mathrm{~h}$ (cort). Cells were pre-treated with RU486 ( $1 \mu \mathrm{M}, 30 \mathrm{~min}$ ) or transfected with PGC-1 $\alpha$ siRNA (40 h). Data were analysed by one-way ANOVA with Bonferroni's post-hoc test; ${ }^{*} P<0.05$ versus control, ${ }^{+} P<0.05$ versus cort

\section{Discussion}

At a physiologically relevant concentration, corticosterone improved the contraction-relaxation properties of primary foetal cardiomyocytes and elicited a striking maturation of myofibrillar content and organisation. This mirrors the in vivo situation where the absence of GR signalling in foetal cardiomyocytes impairs contraction and results in short, disorganised myofibrils with poorly defined Z-discs, ${ }^{5}$ suggesting similar mechanisms for glucocorticoid maturation of cardiomyocyte structure and function in vivo as in vitro.

The glucocorticoid-mediated improvement in contractionrelaxation properties is likely underpinned by improved calcium handling as well as structural changes in myofibrils. As observed in vivo, ${ }^{5}$ glucocorticoid action increased expression of genes encoding the calcium handling proteins SERCA2a and RYR2 as well as contractile proteins (MyHCa) in primary foetal cardiomyocytes. This glucocorticoid induction of mRNAs encoding proteins involved in calcium-induced calcium-release accords with previous findings that glucocorticoids increase cardiac L- and T-type calcium current amplitude and channel density in rat neonatal cardiomyocytes. ${ }^{34-37}$ Moreover, cardiomyocytes isolated from E18.5 $\mathrm{GR}^{-1-}$ foetuses have lower peak calcium channel amplitude, ${ }^{38}$ further supporting a role for glucocorticoid action in regulating sarcolemmal calcium flux. Apart from genes involved in cardiomyocyte depolarisation and initiation of contraction, our data suggest glucocorticoids also promote the later stages of cardiac excitation-contraction coupling, as dexamethasone increased mRNA encoding NCX and several voltage-gated potassium channels, vital for cardiomyocyte repolarisation. However, whilst the RNAseq implicated genes encoding potassium channels as primary GR targets, genes encoding calcium handling proteins were not differentially expressed, and hence their induction by glucocorticoids in foetal cardiomyocytes is most likely a secondary effect of GR signalling.

Glucocorticoid treatment dramatically improved myofibril appearance in foetal cardiomyocytes. The redistribution of a-actinin, from the diffuse punctate staining pattern of untreated foetal cardiomyocytes to the well-defined Z-discs in corticosterone-treated cells probably reflects the fusion of Z-bodies of immature pre-myofibrils to form the Z-discs in mature myofibrils. ${ }^{39}$ In a previous electron microscopy study, contractile filaments were confined to the periphery of rat foetal (E20) myocytes and lacked sarcomeres whereas neonatal rat myocytes contained sarcomeres, ${ }^{8}$ consistent with more mature myofibril structure in neonatal cardiomyocytes compared to foetal. This structural aspect of glucocorticoid-promoted cardiomyocyte maturation depends on glucocorticoid induction of Ppargc1a though other aspects of cardiomyocyte maturation also seen in vivo (Myh6 and Nppa induction) are not and are presumably mediated by other GR-induced transcription regulators. In a recent report, knockdown of PGC-1a or uncoupling of mitochondrial activity by 2,4-dinitrophenol in hESC cardiomyocytes diminished the $a$-actinin banding pattern of contractile filaments, ${ }^{24}$ an effect strikingly similar to that we observed following PGC-1a knockdown in glucocorticoid-treated foetal cardiomyocytes. Given that PGC-1a knock-down also reduced mitochondrial volume and activity in hESC cardiomyocytes, ${ }^{24}$ this strongly suggests that a PGC-1a-driven increase in mitochondrial capacity promotes contractile function through improved sarcomeric integrity, as cardiomyocytes mature. Indeed, glucocorticoid treatment increased basal respiration in foetal cardiomyocytes in a PGC-1a-dependent manner, consistent with the PGC-1adriven effects on both myofibrillar structure and mitochondrial capacity in hESC cardiomyocytes ${ }^{24}$ as well as data from rat neonatal cardiomyocytes showing that dexamethasone increases both intracellular ATP levels and capacity to synthesise ATP. ${ }^{40}$ PGC1- $a$ also promotes production of reactive oxygen species (ROS) in hESC-derived cardiomyocytes. ${ }^{24}$ Interestingly, FOXO3, important for resistance to oxidative stress in cardiomyocytes, ${ }^{41}$ was increased in our RNAseq, suggesting glucocorticoid action concurrently induces the processes that generate ROS as well as mechanisms to alleviate the potential damage they may 
cause. PGC-1 $a$ is already expressed in mouse foetal heart at $\mathrm{E} 15.5,{ }^{23}$ suggesting it may act as a GR coactivator ${ }^{42,43}$ and/or acts downstream of GR to enhance metabolic maturation of foetal cardiomyocytes. Our data support PGC-1a as downstream and a direct target of GR but do not eliminate a role as a coactivator of GR. Indeed, a recent study in mouse islets showed that PGC-1a is both a target and a co-regulator of GR, with downstream effects dependent on the presence of both at regulated promoters. ${ }^{44} \mathrm{~A}$ similar co-dependence in foetal cardiomyocytes might ensure that although expressed, PGC-1a does not exert its full biological effects until corticosterone levels rise and GR is activated. How GR induces Ppargc1a is currently unclear. We were unable to show glucocorticoid regulation of luciferase reporter constructs containing $\sim 4 \mathrm{~kb}$ of the Ppargc1a promoter, despite it being glucocorticoid inducible in mouse BWTG3 hepatoma cells (unpublished data), thus the glucocorticoid responsive element must lie outside of this region.

The postnatal heart heavily relies on oxidative catabolism of fatty acids to produce energy. ${ }^{45}$ Our data support the view that glucocorticoid action in late gestation drives this maturation of cardiac energy metabolism. In addition to PGC-1a induction and independently of new protein synthesis, dexamethasone increased expression of master regulators of lipid/fatty acid oxidation in foetal cardiomyocytes: PPARa, Klf15, and lipin 1. PPAR $a$ co-operates with PGC-1 $a$ to induce genes required for fatty acid uptake and oxidation in the myocardium ${ }^{46}$ Lipin-1, an amplifier of PGC-1a/PPARa mediated control of lipid metabolism that promotes fatty acid oxidation and mitochondrial oxidative phosphorylation in the liver ${ }^{47}$ may play a similar role in heart, where it is both a transcriptional target of, and coactivator of, PGC-1a. ${ }^{48} \mathrm{KIf} 15$, a known GR target, regulates amino acid, lipid, and glucose metabolism ${ }^{49-51}$ and acts with GR to control feed-forward gene-regulatory circuits in lung. ${ }^{52}$ $\mathrm{Klf} 15$ is also a direct regulator of myocardial lipid flux, induced in the mouse heart in the perinatal period. ${ }^{53}$ Thus glucocorticoid action induces a set of master transcriptional regulators which themselves may act in concert with GR in feed-forward circuits to increase cardiomyocyte ATP-generating capacity. As well as master regulators of fatty acid oxidation, dexamethasone markedly induced Plin4, encoding perilipin 4, a lipid droplet coating protein. Plin4 disruption in mice reduces cardiac-lipid content, ${ }^{54}$ suggesting glucocorticoids promote storage of energy substrate in cardiomyocytes as well as increasing capacity to utilise it. It is interesting in this respect that several Slc transporters were glucocorticoid-induced in the presence of cycloheximide, suggesting increased substrate flux into and around the cell as part of a co-ordinated glucocorticoid-mediated increase in energy-generating capacity. A substantial minority of differentially expressed genes were decreased following dexamethasone treatment in the presence of cycloheximide. How this reduction in steady-state mRNA levels occurs within $2 \mathrm{~h}$ is unclear. However, the repressed genes include Hes1, a highly conserved transcriptional repressor required for organogenesis ${ }^{55}$ and a master regulator of GR-dependent gene expression. ${ }^{56}$ In liver, GRdependent antagonism of $\mathrm{NF} K \mathrm{~B}$ at the Hes1 locus, rapidly silences HES1, increasing glucocorticoid sensitivity and altering lipid and carbohydrate metabolism. ${ }^{56}$ Decreased
Hes1 expression in foetal cardiomyocytes may similarly enhance glucocorticoid action, aiding metabolic maturation.

A number of the genes that we identified as glucocorticoid regulated in foetal cardiomyocytes are glucocorticoid regulated in other muscle-related cell types, including rat neonatal cardiomyocytes, embryonic rat $\mathrm{H} 9 \mathrm{C} 2$ myoblasts and mouse C2C12 myotubes. ${ }^{30-32}$ However, despite similarities between glucocorticoid-regulated genes in this and previous studies, none show the same pattern of glucocorticoid-regulated gene regulation, with the cell lines showing many differences to foetal cardiomyocytes. Differences to neonatal rat cardiomyocytes may reflect their prior exposure to glucocorticoid, possibly altering subsequent responses. ${ }^{9}$ Remarkably, of the 173 glucocorticoid-induced genes identified as direct targets of GR in $\mathrm{C} 2 \mathrm{C} 12$ cells, only a third of the induced genes and none of the repressed genes showed similar regulation in foetal mouse cardiomyocytes; three even showed the opposite regulation. Although some of this variation may relate to experimental conditions, the data are consistent with previous demonstrations of the highly cell-specific repertoire of GRregulated genes, ${ }^{10,57,58}$ and illustrate the importance of establishing the glucocorticoid-regulated transcriptome within the relevant primary cell.

These data have wider implications. Despite the routine use of glucocorticoids in preterm babies, little is known of how effects on heart contribute to improved survival of neonates. Our experiments have identified early molecular events triggered by glucocorticoid action in cardiomyocytes during late foetal development and highlight mechanisms likely to be critical for maturation and thus resilience of the foetal heart, in the perinatal period.

\section{Materials and Methods}

Animals; in vivo dexamethasone administration. All animal experimentation was carried out in strict accord with accepted standards of humane animal care under the auspices of the Animal (Scientific Procedures) Act UK 1986 after prior approval by the University of Edinburgh Animal Ethical Review Committee.

Female C57BL/6 mice were maintained under conditions of controlled lighting and temperature. Time-mated females were injected intra-peritoneally with $500 \mu \mathrm{g} / \mathrm{kg}$ dexamethasone or vehicle (saline) at E14.5 then culled $6 \mathrm{~h}$ post-injection. Foetal hearts were collected and stored at $-80^{\circ} \mathrm{C}$ prior to RNA analysis.

Cardiomyocyte cultures. Primary mouse (Mus musculus) foetal cardiomyocytes were isolated from the ventricles of E15.5-E17.5 C57BL/6 foetal hearts and cultured as described, ${ }^{59}$ except that $0.3 \mathrm{mg} / \mathrm{ml}$ collagenase ॥ (Worthington, Lakewood, NJ, USA) was added to the enzyme buffer and cardiomyocytes were cultured on gelatin-covered plates. Isolated cells were $\geq 98 \%$ troponin T-positive cells (Supplementary Figure 1A) and when cultured, cells proliferated and beat spontaneously and synchronously after $\sim 2$ days. Cells were treated with dexamethasone or corticosterone (as stated in the figure legends), with $30 \mathrm{~min}$ pretreatment with $10 \mu \mathrm{M}$ cycloheximide or RU38486 (mifepristone) where appropriate (all purchased from Sigma; Poole, UK). Control cells were treated with vehicle only $(96 \%$ ethanol). For siRNA knock-down, $40 \mathrm{~h}$ prior to dexamethasone administration cells were transfected with GR or PGC-1 $\alpha$ siRNA (catalogue number s67065 and s72015, respectively; Ambion, Austin, TX, USA) using Lipofectamine 2000 (Life Technologies, Paisley, UK) according to the manufacturer's instructions.

Soft-video edge detection. Mechanical properties of spontaneously contracting cardiomyocytes were measured using an optical video edge-detection system (Ionwizard, lonoptix, Milton, MA, USA) with a heated stage $\left(37^{\circ} \mathrm{C}\right)$. Analysis of magnitude and timecourse was performed with Origin6.1 (Originlabs Corporation, Northampton, MA, USA). 
Immunohistochemistry and immunofluorescence. Cells grown on glass coverslips were fixed in $4 \%$ paraformaldehyde and stained according to standard protocols with anti- $\alpha$-actinin antibody (Abcam, Cambridge, UK) or anti- $\alpha$ smooth muscle actin ( $\alpha$-SMA) antibody (Sigma) and troponin T (Abcam). Fluorophore-conjugated secondary antibodies (Alexa Fluor, Life Technologies) were used to detect immunostaining. Scoring of myofibrillar structure was carried out on images by two or three people not involved in the experiment, who were blind to treatment group, according to the following scores: $1=$ randomly scattered punctuate or fuzzy appearance of Z-structures; $2=$ clearly visible sarcomeres (striation, but myofibrils not well organised with indistinct Z-structures; and $3=$ clearly visible, distinct striation and wide discrete Z-discs, high degree of myofibril alignment.

Electron microscopy. Cells grown on plastic coverslips were fixed in 3\% glutaraldehyde in $0.1 \mathrm{M}$ sodium cacodylate, $\mathrm{pH} 7.3$, post-fixed in $1 \%$ osmium tetroxide in $0.1 \mathrm{M}$ sodium cacodylate, then dehydrated and embedded in araldite resin. Ultrathin $(60 \mathrm{~nm})$ sections were cut and stained in uranyl acetate and lead citrate then viewed in a Phillips CM120 Transmission electron microscope (FEI UK, Cambridge, England).

Quantitative (q)PCR. RNA was extracted using a PureLinkTM RNA Mini kit (Life Technologies) according to the manufacturer's instructions and reverse transcribed using a Superscript First Strand Synthesis kit (Life Technologies). Quantitative (q)PCR was carried out using a LightCycler 480 (Roche Diagnostics, Burgess Hill, UK) with a commercial master mix (LC 480 Probes Master) using the Universal Probe Library system (Roche Diagnostics; Table 2). Data were analyzed using the second derivative maximum method. The ratio of levels of the transcript of interest to levels of TATA Binding Protein (TBP) or $\beta$-actin mRNA (as internal control; see figure legends) was determined for each sample.

Western blotting. GR levels were measured by western blot using 1:400 dilution rabbit anti-mouse GR primary antibody (M-20, Santa Cruz Biotechnology, Dallas, TX, USA). Protein levels were measured relative to $\beta$-tubulin levels using an Odyssey infra-red imaging system (Licor Biosciences, Lincoln, NE, USA).

RNAseq. RNAseq was performed by Edinburgh Genomics (University of Edinburgh) on RNA extracted from primary foetal cardiomyocytes treated with $100 \mathrm{nM}$ dexamethasone for $2 \mathrm{~h}$ in the presence of $10 \mu \mathrm{M}$ cycloheximide. Control cells were treated with cycloheximide alone. TruSeq (version 2; Illumina, San Diego, CA, USA) libraries were prepared and sequenced using an Illumina HiSeq 2000 platform (Illumina UK, Little Chesterford, Essex, UK), generating 50 base single-end sequences, yielding 30-50 M reads per sample. Reads were mapped using GSNAP and assigned to exon features with the htseq-count utility of HTSeq ${ }^{60-62}$ (version 0.5.3) in 'union' mode, specifying a non-stranded library, a minimum quality of 20 and mouse genome version NCBI m37 (Ensembl 67) as reference annotation. Counts were then normalised by effective library size, and differential expression (count) assessed, with the use of the DESeq package ${ }^{60}$ (v. 1.9.7) from Bioconductor. ${ }^{61}$ Normalised counts and differential expression measures were placed in a database with in-house tools for data mining. Data were analysed based on fold-change and statistical significance. Enrichment of GO terms in differentially expressed gene sets was assessed with the hypergeometric statistic as implemented in the GOstats package ${ }^{62}$ (v 2.24.0) of Bioconductor.

Cellular bioenergetics analysis. OCR values were measured in real time in primary foetal cardiomyocytes using a Seahorse XF-24 bioanalyser (Seahorse Bioscience, North Billerica, MA, USA). Cells were seeded at a density of $\sim 75000$ per well in a XF-24 microplate $24 \mathrm{~h}$ prior to analysis and treated with corticosterone and/or RU38486 or transfected with PGC-1 $\alpha$ siRNA as described above. One hour prior to analysis media was changed to unbuffered DMEM and cells were incubated at $37^{\circ} \mathrm{C}$ in $0 \% \mathrm{CO}_{2}$. Analysis was performed according to the manufacturer's instructions using an XF assay kit (Seahorse BioScience). Three OCR measurements (performed every $6 \mathrm{~min}$ ) were recorded. To measure mitochondrial reserve, following measurement of OCR, $100 \mu \mathrm{M}$ 2,4-dinitrophenol was injected and then two subsequent measurements were made. Following the assay, cells were trypsinized and counted, and the OCR values corrected for the cell number.

Statistics. All numerical data are presented as mean \pm S.E.M. Statistical evaluation was carried out with Prism (GraphPad) and used Students $t$-test, oneway ANOVA with Bonferroni's post-hoc test or two-way ANOVA with Bonferroni's multiple comparisons post-hoc test, or area under the curve analysis, as appropriate.

\section{Conflict of Interest}

The authors declare no conflict of interest.

Acknowledgements. We thank University of Edinburgh colleagues for their assistance: Biomedical Research Resources staff for assistance with animal care, Edinburgh Genomics for RNAseq. Steve Mitchell for transmission electron microscopy, Val Kelly and Janet Man for quantification of histology and Sheila MacPherson, Mary Diaz, Martin Denvir, and Gillian Grey for helpful discussions and advice. EAR-Z was the recipient of a British Heart Foundation studentship and also British Heart Foundation Fellowship Transition Award. RVR was the recipient of a Medical Research Council studentship. We are grateful for additional support from an Early Career Researcher grant (to EAR-Z) from the Society for Endocrinology and a British Heart Foundation Centre of Research Excellence award.

\section{Author contributions}

EAR-Z, CJK, DGH, MCH, KEC (conception), EAR-Z, KEC (design), EAR-Z, M-AC, RVR, GJG, KG (execution), EAR-Z, JRM, GJG, DRD, CJK, GLS, MCH, KEC (interpretation), EAR-Z, KEC (manuscript preparation).

1. Fowden AL, Li J, Forhead AJ. Glucocorticoids and the preparation for life after birth: are there long-term consequences of the life insurance? Proc Nutr Soc 1998; 57: 113-122.

2. Cole TJ, Blendy JA, Monaghan AP, Krieglstein K, Schmid W, Aguzzi A et al. Targeted disruption of the glucocorticoid receptor gene blocks adrenergic chromaffin cell development and severely retards lung maturation. Genes Dev 1995; 9: 1608-1621.

3. Liggins GC. The role of cortisol in preparing the fetus for birth. Reprod Fertil Dev 1994; 6: 141-150.

4. Miracle X, Di Renzo GC, Stark A, Fanaroff A, Carbonell-Estrany X, Saling E et al. Guideline for the use of antenatal corticosteroids for fetal maturation. J Perinat Med 2008: 36: 191-196.

5. Rog-Zielinska EA, Thomson A, Kenyon CJ, Brownstein DG, Moran CM, Szumska D et al. Glucocorticoid receptor is required for foetal heart maturation. Hum Mol Genet 2013; 22 : 3269-3282.

6. Michelsohn AM, Anderson DJ. Changes in competence determine the timing of 2 sequential glucocorticoid effects on sympathoadrenal progenitors. Neuron 1992; 8: 589-604.

7. Rog-Zielinska EA, Richardson RV, Denvir MA, Chapman KE. Glucocorticoids and foetal heart maturation; implications for prematurity and foetal programming. $\mathrm{J} \mathrm{Mol}$ Endocrinol 2014; 52: R125-R135.

8. Muir TM, Hair J, Inglis GC, Dow JW, Lindop GB, Leckie BJ et al. Dexamethasone-induced differentiation of atrial myocytes in culture. Am J Physiol 1992; 263: H722-H729.

9. Thomassin H, Flavin M, Espinas ML, Grange T. Glucocorticoid-induced DNA demethylation and gene memory during development. Embo J 2001; 20: 1974-1983.

10. So AY, Chaivorapol C, Bolton EC, Li H, Yamamoto KR. Determinants of cell- and genespecific transcriptional regulation by the glucocorticoid receptor. PLoS Genet 2007; 3: e94.

11. John S, Sabo PJ, Thurman RE, Sung M-H, Biddie SC, Johnson TA et al. Chromatin accessibility pre-determines glucocorticoid receptor binding patterns. Nat Genet 2011; 43: 264-268.

12. UM, Shen L, Oshida T, Miyauchi J, Yamada M, Miyashita T et al. Identification of novel direct transcriptional targets of glucocorticoid receptor. Leukemia 2004; 18: 1850-1856.

13. Shipp LE, Lee JV, Yu CY, Pufall M, Zhang P, Scott DK et al. Transcriptional regulation of human dual specificity protein phosphatase 1 (DUSP1) gene by glucocorticoids. PLoS One 2010; 5: e13754

14. Dananberg J, Grekin RJ. Corticoid regulation of atrial natriuretic factor secretion and gene expression. Am J Physiol 1992; 263: H1377-H1381.

15. Arriza JL, Weinberger C, Cerelli G, Glaser TM, Handelin BL, Housman DE et al. Cloning of human mineralocorticoid receptor complementary DNA: structural and functional kinship with the glucocorticoid receptor. Science 1987; 237: 268-275

16. Funder JW. Glucocorticoid and mineralocorticoid receptors: biology and clinical relevance. Annu Revi Med 1997; 48: 231-240.

17. Lemberger T, Staels B, Saladin R, Desvergne B, Aurwerx J, Wahli W et al. Regulation of the peroxisome proliferator-activated receptor a gene by glucocorticoids. J Biol Chem 1994; 269 : 24527-24530.

18. Reddy TE, Pauli F, Sprouse RO, Neff NF, Newberry KM, Garabedian MJ et al. Genomic determination of the glucocorticoid response reveals unexpected mechanisms of gene regulation. Genome Res 2009; 19: 2163-2171.

19. Lemke U, Krones-Herzig A, Berriel Diaz M, Narvekar P, Ziegler A, Vegiopoulos A et al. The glucocorticoid receptor controls hepatic dyslipidemia through Hes1. Cell Metab 2008; 8: 212-223. 
20. Pereira RM, Delany AM, Durant D, Canalis E. Cortisol regulates the expression of Notch in osteoblasts. J Cell Biochem 2002; 85: 252-258.

21. Borgius LJ, Steffensen KR, Gustafsson JA, Treuter E. Glucocorticoid signaling is perturbed by the atypical orphan receptor and corepressor SHP. J Biol Chem 2002; 277 : 49761-49766.

22. Hobert O. Maintaining a memory by transcriptional autoregulation. Curr Biol 2011; 21: R146-R147.

23. Lai L, Leone TC, Zechner C, Schaeffer PJ, Kelly SM, Flanagan DP et al. Transcriptional coactivators PGC-1alpha and PGC-lbeta control overlapping programs required for perinatal maturation of the heart. Genes Dev 2008; 22: 1948-1961.

24. Birket MJ, Casini S, Kosmidis G, Elliott DA, Gerencser AA, Baartscheer A et al. PGC-1 $\alpha$ and reactive oxygen species regulate human embryonic stem cell-derived cardiomyocyte function. Stem Cell Rep 2013; 1: 560-574.

25. Leimeister C, Externbrink A, Klamt B, Gessler M. Hey genes: a novel subfamily of hairy- and enhancer of split related genes specifically expressed during mouse embryogenesis. Mech Dev 1999; 85: 173-177.

26. Montero JA, Giron B, Arrechedera $\mathrm{H}$, Cheng YC, Scotting $\mathrm{P}$, Chimal-Monroy $\mathrm{J}$ et al. Expression of Sox8, Sox9 and Sox10 in the developing valves and autonomic nerves of the embryonic heart. Mech Dev 2002; 118: 199-202.

27. Washington Smoak I, Byrd NA, Abu-Issa R, Goddeeris MM, Anderson R, Morris $\mathrm{J}$ et al. Sonic hedgehog is required for cardiac outflow tract and neural crest cell development. Dev Biol 2005; 283: 357-372.

28. Dyer LA, Kirby ML. Sonic hedgehog maintains proliferation in secondary heart field progenitors and is required for normal arterial pole formation. Dev Biol 2009; 330: 305-317.

29. Frieden LA, Townsend TA, Vaught DB, Delaughter DM, Hwang Y, Barnett JV et al. Regulation of heart valve morphogenesis by Eph receptor ligand, ephrin-A1. Dev Dyn 2010; 239: 3226-3234.

30. Yoshikawa N, Nagasaki M, Sano M, Tokudome S, Ueno K, Shimizu N et al. Ligand-based gene expression profiling reveals novel roles of glucocorticoid receptor in cardiac metabolism. Am J Physiol Endocrinol Metab 2009; 296: E1363-E1373.

31. Kuo T, Lew MJ, Mayba O, Harris CA, Speed TP, Wang JC et al. Genome-wide analysis of glucocorticoid receptor-binding sites in myotubes identifies gene networks modulating insulin signaling. Proc Natl Acad Sci USA 2012; 109: 11160-11165.

32. Ren R, Oakley RH, Cruz-Topete D, Cidlowski JA. Dual role for glucocorticoids in cardiomyocyte hypertrophy and apoptosis. Endocrinology 2012; 153: 5346-5360.

33. Rowe GC, Jiang A, Arany Z. PGC-1 coactivators in cardiac development and disease. Circ Res 2010; 107: 825-838.

34. Whitehurst RM, Zhang M, Bhattacharjee A, Li M. Dexamethasone-induced hypertrophy in rat neonatal cardiac myocytes involves an elevated L-type $\mathrm{Ca}(2+)$ current. $J \mathrm{Mol}$ Cell Cardiol 1999; 31: 1551-1558

35. BenMohamed F, Ferron L, Ruchon Y, Gouadon E, Renaud JF, Capuano V et al. Regulation of T-type Cav3.1 channels expression by synthetic glucocorticoid dexamethasone in neonatal cardiac myocytes. Mol Cell Biochem 2009; 320: 173-183.

36. De P, Roy SG, Kar D, Bandyopadhyay A. Excess of glucocorticoid induces myocardial remodeling and alteration of calcium signaling in cardiomyocytes. J Endocrinol 2011; 209: 105-114.

37. Wagner M, Moritz A, Volk T. Interaction of gonadal steroids and the glucocorticoid corticosterone in the regulation of the L-type $\mathrm{Ca}(2+)$ current in rat left ventricular cardiomyocytes. Acta Physiol (Oxf) 2011; 202: 629-640.

38. Rougier JS, Muller O, Berger S, Centeno G, Schütz G, Firsov D et al. Mineralocorticoid receptor is essential for corticosteroid-induced up-regulation of L-type calcium currents in cultured neonatal cardiomyocytes. Pflugers Arch 2008; 456: 407-412.

39. Dabiri GA, Turnacioglu KK, Sanger JM, Sanger JW. Myofibrillogenesis visualized in living embryonic cardiomyocytes. Proc Natl Acad Sci USA 1997; 94: 9493-9498.

40. Mizuno M, Takeba Y, Matsumoto N, Tsuzuki Y, Asoh K, Takagi M et al. Antenatal glucocorticoid therapy accelerates ATP production with creatine kinase increase in the growth-enhanced fetal rat heart. Circ J 2010; 74: 171-180.

41. Sengupta A, Molkentin JD, Paik JH, DePinho RA, Yutzey KE. FoxO transcription factors promote cardiomyocyte survival upon induction of oxidative stress. J Biol Chem 2011; 286 7468-7478.

42. Knutti D, Kaul A, Kralli A. A tissue-specific coactivator of steroid receptors, identified in a functional genetic screen. Mol Cell Biol 2000; 20: 2411-2422.

43. Yoon JC, Puigserver P, Chen G, Donovan J, Wu Z, Rhee J et al. Control of hepatic gluconeogenesis through the transcriptional coactivator PGC-1. Nature 2001; 413: 131-138.
44. Valtat $\mathrm{B}$, Riveline JP, Zhang $\mathrm{P}$, Singh-Estivalet $\mathrm{A}$, Armanet $\mathrm{M}$, Venteclef $\mathrm{N}$ et al. Fetal PGC-1 $\alpha$ overexpression programs adult pancreatic $\beta$-cell dysfunction. Diabetes 2013; 62 : 1206-1216.

45. Lopaschuk GD, Collins-Nakai RL, Itoi T. Developmental changes in energy substrate use by the heart. Cardiovasc Res 1992; 26: 1172-1180.

46. Finck BN, Kelly DP. Peroxisome proliferator-activated receptor gamma coactivator-1 (PGC-1) regulatory cascade in cardiac physiology and disease. Circulation 2007; 115: 2540-2548.

47. Finck BN, Gropler MC, Chen Z, Leone TC, Croce MA, Harris TE et al. Lipin 1 is an inducible amplifier of the hepatic PGC-1alpha/PPARalpha regulatory pathway. Cell Metab 2006; 4: 199-210.

48. Mitra MS, Schilling JD, Wang X, Jay PY, Huss JM, Su X et al. Cardiac lipin 1 expression is regulated by the peroxisome proliferator activated receptor $\gamma$ coactivator $1 \alpha /$ estrogen related receptor axis. J Mol Cell Cardiol 2011; 51: 120-128.

49. Gray S, Feinberg MW, Hull S, Kuo CT, Watanabe M, Sen-Banerjee S et al. The Krüppel-like factor KLF15 regulates the insulin-sensitive glucose transporter GLUT4. J Biol Chem 2002; 277: 34322-34328.

50. Gray S, Wang B, Orihuela Y, Hong EG, Fisch S, Haldar S et al. Regulation of gluconeogenesis by Krüppel-like factor 15. Cell Metab 2007; 5: 305-312.

51. Haldar SM, Jeyaraj D, Anand P, Zhu H, Lu Y, Prosdocimo DA et al. Kruppel-like factor 15 regulates skeletal muscle lipid flux and exercise adaptation. Proc Natl Acad Sci USA 2012; 109: $6739-6744$.

52. Sasse SK, Mailloux CM, Barczak AJ, Wang Q, Altonsy MO, Jain MK et al. The glucocorticoid receptor and KLF15 regulate gene expression dynamics and integrate signals through feed-forward circuitry. Mol Cell Biol 2013; 33: 2104-2115.

53. Prosdocimo DA, Anand $\mathrm{P}$, Liao X, Zhu H, Shelkay S, Artero Calderon $\mathrm{P}$ et al. Kruppel-like factor 15 is a critical regulator of cardiac lipid metabolism. J Biol Chem 2014; 289: 5914-5924.

54. Chen W, Chang B, Wu X, Li L, Sleeman M, Chan L et al. Inactivation of Plin4 downregulates Plin5 and reduces cardiac lipid accumulation in mice. Am J Physiol Endocrinol Metab 2013; 304: E770-E779.

55. Zhu X, Zhang J, Tollkuhn J, Ohsawa R, Bresnick EH, Guillemot F et al. Sustained Notch signaling in progenitors is required for sequential emergence of distinct cell lineages during organogenesis. Genes Dev 2006; 20: 2739-2753.

56. Revollo JR, Oakley RH, Lu NZ, Kadmiel M, Gandhavadi M, Cidlowski JA et al. HES1 is a master regulator of glucocorticoid receptor-dependent gene expression. Sci Signal 2013; 6: ra103.

57. Yu CY, Mayba O, Lee JV, Tran J, Harris C, Speed TP et al. Genome-wide analysis of glucocorticoid receptor binding regions in adipocytes reveal gene network involved in triglyceride homeostasis. PLoS One 2010; 5: e15188.

58. Phuc Le P, Friedman JR, Schug J, Brestelli JE, Parker JB, Bochkis IM et al. Glucocorticoid receptor-dependent gene regulatory networks. PLoS Genet 2005; 1: e16.

59. Rodgers LS, Schnurr DC, Broka D, Camenisch TD. An improved protocol for the isolation and cultivation of embryonic mouse myocytes. Cytotechnology 2009; 59: 93-102.

60. Anders S, Huber W. Differential expression analysis for sequence count data. Genome Biol 2010; 11: R106.

61. Gentleman RC, Carey VJ, Bates DM, Bolstad B, Dettling M, Dudoit S et al. Bioconductor: open software development for computational biology and bioinformatics. Genome Biol 2004; 5: R80.

62. Falcon S, Gentleman R. Using GOstats to test gene lists for GO term association. Bioinformatics 2007; 23: 257-258.

(c) (i) (2) This work is licensed under a Creative Commons Attribution-NonCommercial-ShareAlike 3.0 Unported License. The images or other third party material in this article are included in the article's Creative Commons license, unless indicated otherwise in the credit line; if the material is not included under the Creative Commons license, users will need to obtain permission from the license holder to reproduce the material. To view a copy of this license, visit http://creativecommons.org/licenses/by-nc-sa/3.0/ 